\title{
METHODS OF FREEZE PROTECTION FOR FRUIT TREES BY MEANS OF RENEWABLE ENERGY SOURCES
}

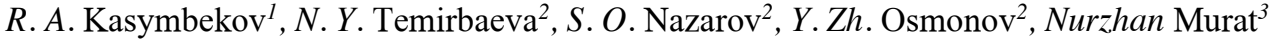 \\ ${ }^{1}$ Machinery researching and Automatics Institute of Kyrgyz Republic National Academy of Sciences, Bishkek, Kyrgyz Republic \\ ${ }^{2}$ Kyrgyz National Agrarian University, Bishkek, Kyrgyz Republic \\ ${ }^{3}$ Almaty University of Power Engineering and Telecommunications Almaty, Republic of Kazakhstan
}

\begin{abstract}
As the Earth climate changes, the current horticulture gives rise to an acute issue - protecting fruit trees from spring frosts and their root system from freezing in severe winters with little snow. The authors substantiated the methods of how to protect fruit trees from frost and their root system from freezing, as well as a method of how to control their phenological phases based on the study of the heatmass-exchange intensification in a certain soil area occupied by the root system of a tree with various engineering aids to be designed. The aforesaid method is based on the operation of a heat and cold separator, which makes it possible to intensify heat transfer and expand the area of specific heat loads removed using a coolant - potassium salt brine (aqueous $30 \% \mathrm{KCL}$ solution). The test results have shown that the coolant heated by the heat of the soil to a temperature of $12^{\circ} \mathrm{C}$, gradually moving up at a depth of $0.9 \mathrm{~m}$, heats the soil to $7^{\circ} \mathrm{C}$ at a depth of $0.5 \mathrm{~m}$ and up to $1^{\circ} \mathrm{C}$ on the surface of the earth at an ambient temperature of up to $-10^{\circ} \mathrm{C}$. The heat of the lower soil layers comes up to the surface; in the soil area occupied by the root system, the temperature is redistributed, stabilized in a state that excludes freezing of the root system of the fruit tree. A rational value of the effective head has been determined to be equal to $2200 \mathrm{H} / \mathrm{m} 2$ at the depth of the heated soil surface up to $1 \mathrm{~m}$, with a specific heat flow of about $4 \cdot 105 \mathrm{~W} / \mathrm{m} 2$. In addition, a rational flow rate of the coolant is set equal to $(1.5 \ldots 2.5)$ Gmin to produce more optimal heat transfer and additional body force of the heat and cold separator. The method of controlling the phenological phases of fruit trees by heating or cooling a certain soil area occupied by the root system is possible using an installation that generates power from the renewable resources (solar energy, wind or biogas plant), depending on climatic conditions and terrain.
\end{abstract}

\section{Introduction and literature review}

Maintaining a stable yield of fruit trees is the key purpose of agro-engineering measures carried out annually. At the same time, the use of methods of heat protection of trees from frost and the management of their phenological phases becomes topical in today's horticulture, especially in areas of risky agriculture [1], [2].

Efficient application of these methods has a significant effect on the commencement and duration of individual phenological phases of trees and on the entire vegetative process, and provides their protection from spring frosts and protection of the root system of trees from freezing in severe winters. The upset of the heat regime negatively affects the winterization of trees, that is, their frost resistance and winter hardiness [3], [4].

Historical information shows that for the heat protection of fruit trees, gardeners mainly used and still use "old-fashioned methods": smoking, watering, wrapping, sprinkling, etc. However, these methods are ineffective, they restrain the flower blooming for only 3-
5 days. Such a period of containment of flower blooming is not enough to protect from frost, especially in areas of risky farming. Consequently, a significant part of the crop is lost [5], [6]. For example, in the Kyrgyz Republic in the year of frost (2017), the yield of fruit and berry crops was 33.7 quintal/ha and $172,459.7$ tons were harvested. The total area of fruit and berry crops in Kyrgyzstan in 2017 was 51,175 hectares and is growing every year. In 2018, the yield was 48.1 quintal/ha (yield without frost). If in 2017 the yield would have been as in 2018 , then the harvest would have been 246,152 tons, that is, the crops failed in 2017 for 73,692 tons. And the crop loss from frost was about $30 \%$ [7].

Small tree roots require heat protection. The critical freezing point of small roots is $-12^{\circ} \mathrm{C}$. The roots freeze and die below this temperature. This is especially true in severe winters with little snow [8].

The present-day commercial horticulture needs effective methods of heat protection of fruit trees allowing them to manage their phenological phases to obtain stable annual yields and increase the longevity of trees. Managing phenological phases (lengthen or

\footnotetext{
* Corresponding author: ryskul.kasymbekov@mail.ru
} 
shorten) requires a thorough knowledge of the physiological state, biology, morphological features and characteristics of fruit trees. In addition, it is necessary to skillfully and efficiently use external environmental factors of a certain area, taking into account their particular characteristics (terrain, meteorology, air humidity, etc.) The only test runs are insufficient to fully address such a comprehensive problem. The basis for methods of conditioning sustainable management of phenological phases of fruit trees requires theoretical studies that use objective laws of heat transfer in a porous system, followed by test runs to check their adequacy within acceptable values of confidence intervals.

Various approaches of heat protection of trees and engineering aids for their introduction have been developed: in devices containing hollow thermopiles [9], [10], where the heat energy is accumulated by circulating ambient air into the lower layers of the soil. The ambient air propagate in the lower layers of the soil in summer time and is accumulated until the point of necessary heat protection of trees. The disadvantage of these engineering solutions is the insufficient potential of the accumulated heat energy and its performance capacity.

Available are heat pipes [11], [12], [13] with zones of evaporation and condensation, and equipped with an ammonia tank. The drawback of these pipes is they do not offer self-regulation of the ground temperature. To eliminate this drawback, another heat pipe has been designed [14] that operates with a twocomponent coolant, namely, ammonia is used as the main coolant, and freon gas is used as a low-boiling additive.

Available are thermosyphons [15], [16], where the fluid has the ability to transition from a liquid state to a gaseous state and back, respectively, having an evaporator and condenser sections. The drawback of thermosyphons is that a relatively high thermal head builds up between the condenser section and the heat consumer during heat transfer.

An approach for protecting fruit trees from frost by friction between nylon and polyethylene is proposed. In this regard, the tree is covered with plastic wrap and it, in turn, is covered with a nylon fine mesh. Specifically, as driven by atmospheric effects, friction occurs between bodies and static electricity appears, which, interacting with the magnetic field of the ground, prevents the cooling of the soil under the tree [17].

There are chemical methods of protecting plants from frost: by using a solution of contact insectofungicide - dinitroorthocresol; 2,4-dinitro-6methyphenol and others [18], [19], [20], [21], [22], which act on the blossoming buds inhibit their growth for 8-17 days. The disadvantages inherent in chemicals are associated with increased concentrations when they are in use, causing burns of the tree leaves.

Technologies have been designed to protect thermophilic crops from frost in open and protected ground, including a system of agrometeorological tracking and forecasting based on the Elagr-2 measuring suite. These technologies include a number of beneficial protection methods: the method of artificial fogging; dynamic method; thermal methods based on heatgenerating agents and local heat sources. The application of these methods is linked with high costs, for example, a MI-8 helicopter is used, hardware (Dutch-made) worth USD 28,000-30,000, etc.

There are simple, cheap and affordable ways to protect trees from frost: a heat-shielding emulsion is prepared, which contains wood or straw flour, a 4-6 percent aqueous solution of non-monogenic surfactants in a ratio of 1:2. A foaming agent PO-1, a mixture of alkyldimethylamine oxide $\left(\mathrm{C}_{10}-\mathrm{C}_{18}\right)$ with edolatin alkylsulfade and others, which are not harmful to the trees can be used as a surfactant. The finished emulsion is sprayed with industrial sprayers causing a protective film on the surface of the tree as the surfactants adhere to each other. Since wood has low thermal conductivity, this coating provides reliable frost protection. At the end of frost, by the action of atmospheric phenomena (precipitation, wind) and direct sunlight, surfactants dissolve, and, in the course of changing the shape of the tree branches, the film destroys.

A brief analysis shows that the agro-engineering measures, the protection of fruit trees from frost takes pride of place, especially in areas of risky agriculture. By rational use of external weather conditions and knowledge of the biology and physiology of fruit trees, it is possible to control their phenological phases by applying different methods with a variety of engineering aids/

Thus, the prospects for the development of horticulture pose an issue of protecting fruit trees from frost. This issue is particularly acute in areas of risky agriculture. One of the ways to address this issue is making modern protection methods available that can be used to protect fruit trees from spring frosts, their root system in severe winters, manage phenological phases, as well as to design appropriate engineering aids for their introduction. As a source of energy, it is advisable to use renewable resources (solar energy, wind power, biogas plants, etc.), depending on the geography, terrain and climatic conditions.

The purpose of the study is to protect fruit trees from frost and control their phenological phases by cooling or heating a certain area of soil occupied by the tree root system.

Objectives of the study:

- theoretical research;

- substantiation of a method for protecting fruit trees from spring frosts, and roots from freezing, design of a heat and cold separator;

- selection and substantiation of a method for controlling phenological phases of fruit trees and design of an installation for its introduction. 


\section{Materials and methods}

\subsection{Method of freeze protection for fruit trees}

Distinctive features of the proposed method are as follows:

- redistributes, stabilizes and maintains the temperature in a certain area occupied by the root system of the tree from 0 to $-1^{0} \mathrm{C}$ by shifting the heat from the soil depth to the surface and sending the cold from the surface of the soil to its depth;

- cools down the soil from the surface deep below the center of the soil area occupied by the root system of the southern, south-western and south-eastern sides of the tree crown (at two, three or more points), taking into account climatic conditions, terrain and age of the tree.

The proposed method misses the circulation of ambient air through the lower soil layers, which excludes sharp fluctuations in soil temperature detrimental to the root system of the tree. This method also excludes the circulation of groundwater, which makes it possible to be used in any horticulture zone.

For making this method happen, an annular heat and cold separator as a heat pipe with closed evaporating-condensing loop where a coolant circulates have been designed (Fig. 1).

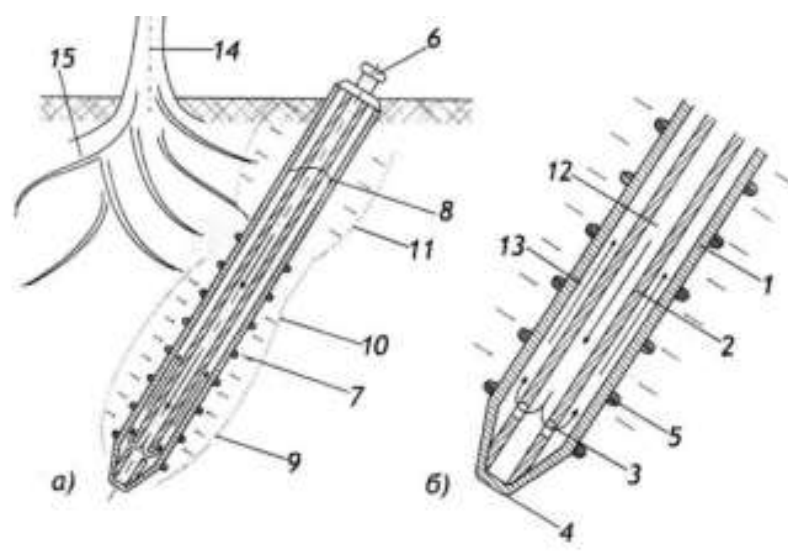

Fig. 1. Heat and cold separator:

1-housing; 2-separator; 3-holes; 4-tip; 5-ribs; 6-plug; 7evaporator; 8-condenser; 9, 10-heat supply zones; 11-heat removal zone; 12-coolant; 13-brine; 14-fruit tree trunk; 15-root system.

The heat and cold separator is installed from the south, south-west and south-east sides of the fruit tree, obliquely so that the end part, where the tip 4 with ribs 5 is located, in the middle part of the soil area, where the bulk of the tree root system is concentrated. The upper end of the heat and cold separator up to the plug 6 is located in the interface zone: soil-air.

The heat and cold separator operates as described below. Through the plug 6 , a solution of the coolant 12 (potassium salt brine) is filled into the heat pipe housing 1. The concentration of the coolant is selected so that it has a freezing point below the soil temperature in the coldest period of winter. The operating temperature for the heat pipe depends on the concentration of the coolant. Intensification of heat and mass transfer processes inside the heat pipe housing 1 is provided by the separator 2 with holes 3 due to its coaxial arrangement with the heat pipe to form annulus.

Cold brine of potassium salt with a higher specific gravity goes down into the separator 2 by gravity and through the holes 3 enters the annulus between the housing 1 and the separator 2 . In this case, heat coming from the depth of the soil flows to the brine through the ribs 5 in the zone 9 of the main heat supply. Some heat is also applied to the brine in zone 10 (sliding zone). The heat is continuously supplied to the brine until the temperature difference between the brine and the soil becomes zero. Now, the heated brine reaches the heat removal zone 11 .

In zone 11 , the heat from the brine 13 will go through the housing and the rib 5 to the cold soil section adjacent to the soil-air interface, creating favorable conditions for the wintering of the root system in the subsurface layer. The cooled brine re-enters the separator 2 , taking up the initial state, and the process of heat and mass transfer is repeated.

The heat and cold separator is capillary-porous in structure. Calculation of the hydrodynamic characteristics of this structure is possible using the known value of the effective head in the capillary annular space. For the wick element, a differential equation of momentum transfer is recommended in the form: [23], [24], [25]

$$
\begin{aligned}
& g\left\{\frac{1}{\rho_{\mathrm{K}}} \cdot \frac{d}{d y} \cdot\left[G_{\mathrm{K}}^{2}(\mathrm{y})\right]\right\}=\rho_{\mathrm{K}} \cdot q+2 \delta \cdot \frac{d}{d y}\left[\frac{1}{R(\mathrm{y})}\right]- \\
& \frac{\varepsilon \cdot \mu_{\mathrm{K}} \cdot G_{\mathrm{K}}(\mathrm{y})}{\mathrm{K}_{\mathrm{y}} \cdot \rho_{\mathrm{K}}}
\end{aligned}
$$

where, $\rho_{\varkappa}$ is the density of the coolant (brine); $g$ is the acceleration of gravity; $G_{\mathscr{H}}(y)$ is the specific flow rate of the coolant; $q$ is the specific heat flow; $\delta$ is the surface tension coefficient; $R$ is the radius of the coolant meniscus; $\varepsilon$ is the porosity; $\mu_{\mathscr{N}}$ is the dynamic viscosity of the coolant; $K_{y}$ is the conditional permeability coefficient.

The specific flow rate of the coolant $G_{\mathscr{H}}(y)$ versus the coordinate $y$ characteristic is given by:

$$
G_{\varkappa}(y)=\left(\frac{q \cdot L \cdot h}{r \cdot \varepsilon \cdot F_{\phi}}\right) \cdot\left[\beta+\left(1-\frac{y-h}{h}\right)\right],
$$

where, $L$ is the surface length; $h$ is the surface height; $r$ is the specific heat of evaporation; $F_{\phi}$ is the wick section; $\beta$ is the coefficient of evaporation.

Integrating the equation (1) within the limits $h \geq y \geq 0$ taking into account the characteristic (2) yields the general integral energy equation: 


$$
\begin{aligned}
& \frac{1}{Q_{\varkappa}} \int_{h}^{0} d\left\{\left(\frac{q \cdot L \cdot h}{r \cdot \varepsilon \cdot F_{\phi}}\right)^{2}\left[\beta+\left(1-\frac{y-h}{h}\right)\right]\right\}^{2}=\int_{h}^{0} Q_{\varkappa} \cdot g \cdot d y+2 G \int_{R_{h}}^{R_{0}} d\left[\frac{1}{R_{y}}\right] \\
& -\int_{h}^{0} \frac{\varepsilon \cdot \mu_{\varkappa} \cdot q \cdot L \cdot h}{K_{y} \cdot Q_{\varkappa} \cdot r \cdot \varepsilon \cdot F_{\phi}} \cdot\left[\beta+\left(1-\frac{y-h}{h}\right)\right] d y .(3)
\end{aligned}
$$

Since the forces of gravity act when the fluid moves in and out of the wick, the value of the first term on the right-hand side of equation (3) varies within the limits $h \geq y \geq 0 h \geq L$, and the coefficient $\beta$ is not a function of $y$.

Integration of equation (3) demonstrates that the left side of the equation, which takes into account the contribution of inertial forces to the pressure balance, is much less than the right side of the equation. Therefore, when calculating the effective head $\Delta P_{g+\kappa a n}$, it is possible to use the characteristic

$$
\Delta P_{g+\text { каn }}=\frac{q \cdot h \cdot \mu_{\varkappa} \cdot F_{\phi} \cdot(\beta+1,5)}{K_{y} \cdot r \cdot \rho_{\varkappa} \cdot F_{\phi}} .
$$

The conditional permeability coefficient is calculated by the formula:

$$
K_{y}=\frac{\mu_{\varkappa} \cdot m_{\varkappa} \cdot h}{Q_{\varkappa} \cdot \Delta P_{g+\text { Kan }} \cdot F_{\phi}}
$$

or by empirical dependence

$$
K_{y}=5,504 \cdot 10^{-7} \cdot\left(\frac{b_{r}}{a_{r}}\right)^{-1,29} \text {. }
$$

\subsection{Method for controlling phenological phases of fruit trees}

Efficient application of the method for controlling the phenological phases of fruit trees largely relies on the nature of the distribution of their roots.

The phenological phases of fruit trees by heating or cooling a certain area of soil occupied by the root system are controlled using an installation that generates electrical power from the renewable resources (solar energy, wind power or biogas plant), depending on climatic conditions and terrain [26], [27].

The layout is shown in Fig. 2, where the main element is a special box 6, which is installed in the soil, where the root system of the fruit tree 9 is located.

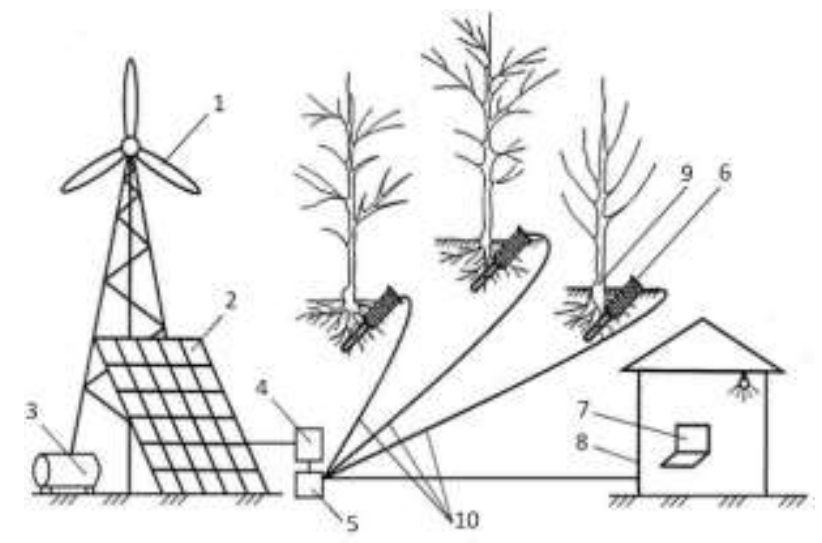

Fig. 2. The installation for controlling the phenological phases of fruit trees:

1-wind turbine; 2-solar battery; 3-biogas plant; 4-multi-stage multiplier; 5-generator; 6-special box; 7-computer; 8-control room; 9-fruit tree; 10-cable.

Based on the availability and magnitude of wind speed, solar radiation or biomass, a certain horticultural zone, the wind turbine 1, solar batteries 2 or the biogas plant 3 are used, respectively, which, through the multistage multiplier 4, drives an electric generator connected to a heating element of the special box 6 via the battery. The temperatures inside the special box are controlled and regulated by the computer 7 installed in the control room 8 .

The special box (Fig. 3) consists of two pipes 1 different in diameter, where the end part with a smaller diameter is equipped with a pointed blind tip, inside which heating elements 2 are installed, and the other part with a large diameter is equipped with the ammonia cooler 3 .

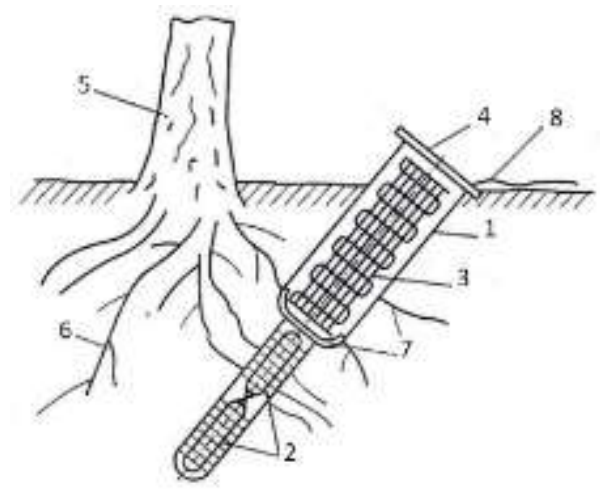

Fig. 3. The special box

1-housing; 2-heating elements; 3-cooler; 4-plug; 5-fruit tree; 6root system; 7-Teflon partition; 8-cable.

The Teflon partition 7 is available between the mentioned parts of the special box. The ammonia cooler has the plug 4. Power is supplied to the heating elements using cable 8 from one of the types of renewable resources. 


\section{Results}

The the effective head $\Delta \mathrm{P}_{g+\text { кап }}$ versus the height of the heated surface of the heat and cold separator $h$ calculated by formulas (4) and (6) is shown in Fig. 4.

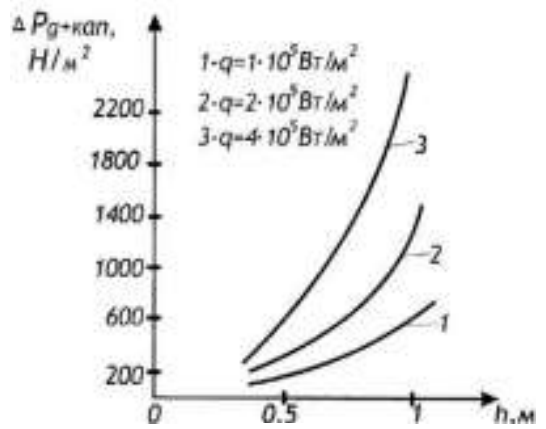

Fig. 4. The effective head $\Delta \mathrm{P}_{\mathrm{g}+\text { кan }}$ vs. the height of the heated surface, $h$, of the heat and cold separator $\Delta \mathrm{P}_{\mathrm{g}+\text { кап }}=\mathrm{f}(\mathrm{h}) \Delta \mathrm{P}_{\mathrm{g}+\text { кап }}=\mathrm{f}(\mathrm{h})$

The characteristic $\Delta \mathrm{P}_{g+\text { кап }}=f(h)$ shows that with an increase in the heat load $q$, the increase in the effective head is intense. With a specific heat flux $q=4 \cdot 10^{5} \mathrm{~W} / \mathrm{m}^{2}$ at the height of the heated surface $h=$ $I m$, the effective head is more than $\Delta \mathrm{P}_{g+\text { кап }} \geq 2200$ $\mathrm{N} / \mathrm{m}^{2}$.

In addition, the size of the effective head $\Delta \mathrm{P}_{g+\text { кап }}$ is affected by the structure and geometry of the wick.

However, at increased heat loads $q$, a loss of stability of the near-wall pulsating liquid layer can occur, the mesh cells are blocked by vapor bubbles, and the liquid is no more accessed to the heating zone, resulting in a significant increase in thermal resistance and wall burnout.

The study results of the effect of body forces and fluid flow on heat transfer are shown in Fig. 5.

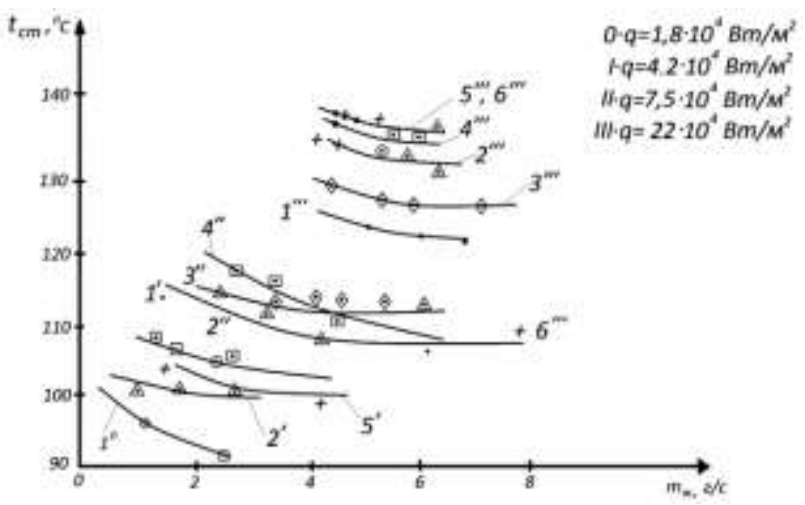

Fig. 5. The temperature of the outer wall of the heat and cold separator versus the flow rate of the coolant $\left(\mathrm{t}_{\mathrm{cm}}=\mathrm{fm}_{\mathrm{w}}\right)$ : 1- $\oplus$ mesh $0.14 ; 2-\Delta$ structure $3 \cdot 0.14 ; 3-\ominus$ grid $0.24 ; 4-\square$ structure $3 \bullet 0.28 ; 5-+$ structure $0,08 \cdot 0,14 \cdot 0,14 ; 6-\bullet$ structure $0,08 * 0,28 * 0,28$.

The annular vertical heating surface made of stainless steel was cooled from the minimum possible liquid flow rate $G_{m i n}$, at which the minimum wall temperature is set, to the liquid flow rate of about 7.5
$G_{m i n}$. For pressure $P=0.1 \mathrm{MPa}: m_{j}=(1 \ldots 7.5) G_{m i n}$, the mesh and wall are stainless steel.

The analysis of the characteristic $t_{\mathrm{cT}}=f\left(m_{\mathrm{w}}\right)$ shows that for the liquid flow rates equal to $(1.5 \ldots 2.5)$ $G_{m i n}$, there is a slight decrease in the average heat transfer coefficient for almost all capillary-porous structures and specific heat fluxes $q$. With a further increase in the coolant flow rate from 2.5 to $7 G_{m i n}$, a slow increase in the heat transfer coefficient is observed.

Thus, for the discussed capillary-porous cooling system, in order to intensify the heat transfer process and create an additional body force, the liquid flow rate should be maintained equal to

$$
G_{\min }=(1,5 \ldots 2,5) \frac{q}{r} \text {. }
$$

A further increase in the flow rate of the liquid is impractical, as it leads to an increase in power consumption for pumping the liquid without a noticeable increase in the heat transfer coefficient. Increasing the coolant flow rate within $m_{\%}=(0,5 \ldots 0,8) \mathrm{g} / \mathrm{s}$ reduces the average wall temperature. In the range of changes in the specific heat flux $q=(4 \ldots 22) \cdot 10^{4} \mathrm{~W} / \mathrm{m}^{2}$, the average temperature changed from $100{ }^{\circ} \mathrm{C}$ to $140{ }^{\circ} \mathrm{C}$, and for a given $q$, the minimum value of $t$ corresponds to the structure of the smallest thickness.

The results obtained in test runs of the operation of the heat and cold separator are listed in Table 1.

Table 1. Test results of the heat and cold separator

\begin{tabular}{|c|c|}
\hline $\begin{array}{c}\text { The depth of } \\
\text { thermocouple penetration, } \\
\mathrm{m}\end{array}$ & $\begin{array}{c}\text { Soil and air } \\
\text { temperature, }{ }^{0} \mathrm{C} \text { soil/air }\end{array}$ \\
\hline 0.9 & $12 /-10$ \\
\hline 0.5 & $7 /-8$ \\
\hline 0.1 & $1 /-4$ \\
\hline
\end{tabular}

Experiments show that the coolant - potassium salt brine - is an aqueous $30 \% \mathrm{KCl}$ solution, heated by the soil heat through the metal housing of the heat and cold separator to a temperature of $12{ }^{\circ} \mathrm{C}$ at a depth of 0.9 $\mathrm{m}$, gradually rising, heats the soil to $7{ }^{\circ} \mathrm{C}$ at a depth of $0.5 \mathrm{~m}$ and up to $1{ }^{\circ} \mathrm{C}$ on the surface. In this case, the air temperature, respectively, was $-10{ }^{\circ} \mathrm{C},-8{ }^{\circ} \mathrm{C}$ and $-4{ }^{0} \mathrm{C}$. The experiments were conducted in February in the morning hours. The heat of the lower soil layers is carried to the surface by the coolant circulating in the heat and cold separator. Consequently, in the soil area occupied by the root system, the temperature is redistributed and stabilized in a state that excludes freezing of the root system of the fruit tree. The coolant is a slightly saturated to supersaturated solution. Cooling from the soil surface to the depth occurs below the center of the soil area from the southern side of the tree crown at two, three or more points.

The environmental, economic and social assessment of the paper will be more objective considering the type of fruit tree prevailing in this 
geographical area. The choice of the type of fruit tree is a function of the terrain, climatic features and type of soil.

Among fruit trees widespread in the Kyrgyz Republic, the apple tree occupies more than $70 \%$ of the area of existing horticulture and is 51.4 thousand hectares, with an average yield of $49.3 \mathrm{c} / \mathrm{ha}$ [7]. At average the root system of an apple tree penetrates to 2.6 $\mathrm{m}$, and the average depth of soil freezing in the horticulture zones is $0.935 \mathrm{~m}$. Based on this, the length of the heat and cold separator can be selected equal to 1 $\mathrm{m}$.

Referring to the R\&D information, the main indicators of how the proposed methods are beneficial can be listed.

Economic (commercial), social and environmental benefits are affordable by applying these methods.

\section{Discussion}

Prospects for the development of horticulture give rise to new challenges related to the protection of fruit trees from frost and the root system from freezing in severe winters with little snow. One of the solutions to these problems is to intensify heat and mass transfer processes in a certain area of soil occupied by the root system of a tree using various engineering aids.

The proposed heat and cold separator enables to increase the intensity of heat transfer and expand the area of specific heat loads removed as compared with heat pipes.

For this, , as is the case in heat pipes, there are forces in addition to the capillary forces that can be used to produce the necessary excess of fluid in the cross section of the capillary-porous system.

The results are explained by the presence of body forces that contribute to a more active removal of heat from the heating zone, and, conversely, cold from the cooling zone. The advantage of the heat and cold separator over the thin-film evaporators is pertinent to lower liquid consumption.

An increase in the effective head above this value is not recommended, since this causes a significant increase in thermal resistance and wall burnout.

Studies of the liquid flow rate to produce an optimal heat transfer process and additional body force have shown that it is necessary to maintain the liquid flow rate equal to $(1,5 \ldots 2,5) G_{\min }$. A further increase in the consumption of inertness is not advisable, since it causes an increase in power consumption for pumping liquid without increasing the heat transfer coefficient.

\section{Conclusion}

1. As the today's industrial horticulture advances, the role of special engineering aids and hardware, used to protect fruit trees from frost, ramps up and makes it possible to control their phenological phases, cause a change in the timing of flowering, growth rates, reduce the vegetation of individual organs, without any risk for the flowers to die.

2. Rational ways of how to protect fruit trees from frost and control their phenological phases have been substantiated, engineering aids (heat and cold separator and special box) have been designed to make these methods happen. It has been found that the value of the effective head is influenced by the heat load, structure and geometry of the wick. With a specific heat flux of about $4 \cdot 10^{3} \mathrm{~W} / \mathrm{m}^{2}$ at a height of heated surface up to $1 \mathrm{~m}$, the effective head can reach up to $2200 \mathrm{~N} / \mathrm{m}^{2}$. No circulation of cold ambient air to regulate the soil temperature makes it possible to use these methods in all zones of horticulture, especially in areas of risky farming. The engineering aids are self-contained, easy to manufacture and maintain, the coolant is available. Power supply by renewable energy sources, depending on the geography of the area.

3. The hydrodynamic characteristic of the capillary-porous heat and cold separator in the form of the effective head is determined taking into account the heat load, structure and geometry of the wick. This characteristic was used to determine the optimal flow rate of the coolant: to produce an optimal heat transfer process and additional body force, it is necessary to maintain the flow rate equal to $(1.5 \ldots 2.5) \mathrm{G}_{\min }$.

4. The use of a coolant - an aqueous $30 \%$ solution of KCL (potassium salt) in the proposed heat and cold separator allows transforming soil heat equal to $12^{\circ} \mathrm{C}$ at a depth of $0.9 \mathrm{~m}$ to a temperature of $7^{\circ} \mathrm{C}$ at a depth of $0.5 \mathrm{~m}$, then to a temperature of $1{ }^{\circ} \mathrm{C}$ on the surface, when the ambient temperature changes within $10 \ldots-4^{\circ} \mathrm{C}$.

Environmental, economic and social arguments of the paper can be used to evaluate the effectiveness of the designed engineering aids, which show: increasing annual yield up to $30 \%$ and is sustainable; enhancing winter and frost resistance of the fruit tree, horticultural culture through the use of advanced technologies and creating conditions for the development of new land plots..

\section{References}

1. Rudnytska G. Analysis of promising methods for protection of fruit trees generative organs from spring frosts. Technology audit and production reserves. 2015. V.3. №1(23), Pages 64-69.

2. Vincent W.J., Heusinkvelda J., Antoon van Hooftb, Bart Schilperoortc, Peter Baasde, Marieclaire ten, Veldhuisf, Bas J., H.van de Wielg. Towards a physics-based understanding of fruit frost protection using wind machines. Agricultural and Forest Meteorology. Volumes 282-283, 15 March 2020, 107868.

3. John G. Duman, Michael J.Wisniewski. The use of antifreeze proteins for frost protection in sensitive crop plants. Environmental and 
Experimental Botany. Volume 106, October 2014, Pages 60-69.

4. Andrew D. Richardson, Trevor F. Keenan, Mirco Migliavacca,'Youngryel Ryu, Oliver Sonnentag, 'Michael Toomey. Climate change, phenology, and phenological control of vegetation feedbacks to the climate system. Agricultural and Forest Meteorology. Volume 169, 15 February 2013, Pages 156-173.

5. Yu. F. Yakuba. Technological measures for the protection of thermophilic fruit crops under winter stress. Fruit growing and viticulture of South Russia, 2013, No. 22 (4), pp. 129-136.

6. E. L Bydder., M. D. Lowe. Frost protection with artificial fogs. - New Zealand. N.Z.J. Exper. Agr. 1985, vol. 13, No. 3, pp. 195-200.

7. Summary of the harvest of agricultural crops by regions and districts of the Kyrgyz Republic as of December 20 , 2019. http://stat.kg/statistics/selskoe-hozyaistvo/).

8. Viviana Tudela, Fernando Santibáñez. Modelling impact of freezing temperatures on reproductive organs of deciduous fruit trees. Agricultural and Forest Meteorology. Volumes 226-227, 15 October 2016, Pages 28-36.

9. US Patent No. 3561157, IPC A01G 13/06, 1971.

10. A. B. Bakhtadze, Sh. A. Mestvirishvili, I. G. Shekriladze. Inventor's certificate of the USSR No. 969205. Method of heat protection of plants and device for its implementation. IPC A01G, 13/06. 1982.

11. French Patent No. 2402177, IPC F28D 15/00, 1979.

12. French Patent No. 2428222, IPC F28D 15/00, 1980.

13. Dr. D.G. Hessayon. The easy care garden expert.Moscow Kladez (Russian edition), 2009. - p. 128.

14. I. G. Shekriladze, Sh. A. Mestvirishvili, G. V. Ratiani, D. G. Russhivili. Inventor's certificate of the USSR No. 996839. Heat pipe. IPC F28D 15/00, 1983.

15. V. M. Butrin, V. V. Dvirnyi, M. I. Sokolov, E. V. Aferenko. Patent of the Russian Federation No. 2261405. Thermosyphon. IPC F28D 15/02, 2005.

16. Yu. F. Yakuba. Patent of the Russian Federation No. 2522522. Method of handling garden trees and grapes for protection from low temperatures and spring frosts. IPC A01G 7/06, 2014.

17. I. I. Lavreichuk, I. A. Kretov. Inventor's certificate of the USSR No. 522837. Method for increasing the heat-conserving capacity of polymer film covers for plant protection. IPC A01G 13/02, A01G 9/26, 1976.

18. Guillaume Charrier, Jérôme Ngao, Marc Saudreau, Thierry Améglio. Effects of environmental factors and management practices on microclimate, winter physiology, and frost resistance in trees. Frontiers Plant Science, 28 April 2015. doi: 10.3389/fpls.2015.00259.
19. CY. Choi, W. Zimmt, G. Giacomelli. Freeze and frost protection with aqueous foam-Foam development. American Society for Horticultural Science. Volume 9, Pages 661-669.

20. V. A. Stepanov, A. E. Menshikov et al. Patent of the Russian Federation No. 2198499. Methods of protecting fruit trees from frost. IPC A01G 7/06, A01N 33/22, 2003.

21. S. K. Sastri, J. R. Philips, C. T. Morrow, Prediction of sprinkler off-times during frost protection of apple buds: a heat transfer model. USA. J. Agr. EnggRes. 1985, vol. 31, No. 4, - pp. 283-295.

22. T. Holybowich. The protection of the blooming gardens from spring frosts. - Poland. Sadnowoczesny, 1991, vol. 1, 5. - pp. 5-12.

23. V. M. Polyaev, A. A. Genbach. Management of heat transfer in porous structures: Proceedings of the Russian Academy of Sciences, Moscow: Energy and Transport, vol. 38, No. 6, 1992, pp. 105-110.

24. Genbach, A. A. Thermal characteristics of capillary-porous heat exchangers. Collection. Power engineering, heat communications and higher education in modern conditions. Almaty, 2002, pp. 73-76.

25. V. Polyaev. Control of Heat Transfer in a Porons Cooling System. Second world conference on experimental heat transfer, fluid mechanics and thermodynamics. - Dubrovnik, Yugoslavia. 1991, - pp. 639-644.

26. Nurzhan Murat, Y. J. Osmonov, B. S. Toktonaliev, Patent of the Kyrgyz Republic No. 1972. Device for controlling the phenophases of fruit trees. IPC A01G 7/00 / 2017. Bul. No. 8.

27. Y. J. Osmonov, Nurzhan Murat., E. Zh. Abdulin. Method control of the phenophases of fruit trees by heating or cooling the plant with wind or solar energy. - Bishkek: Bulletin of K. I. Skryabin Kyrgyz National Agrarian University, No. 1, 2014, pp. 17-23. 